Article

\title{
A Genetic Polymorphism in the Pannexin1 Gene Predisposes for The Development of Endothelial Dysfunction with Increasing BMI
}

\author{
Filippo Molica ${ }^{1, *(\mathbb{C})}$, Alessandra Quercioli ${ }^{2}$, Fabrizio Montecucco ${ }^{2}\left(\right.$, Thomas H. Schindler $^{2}(\mathbb{D}$, \\ Brenda R. Kwak ${ }^{1,2}$ and Sandrine Morel $^{1}$ (D) \\ 1 Department of Pathology and Immunology, University of Geneva,1211 Geneva, Switzerland; \\ brenda.kwakchanson@unige.ch (B.R.K.); sandrine.morel@unige.ch (S.M.) \\ 2 Department of Medical Specialities-Cardiology, University of Geneva, 1211 Geneva, Switzerland; \\ alessandra.quercioli@libero.it (A.Q.); fabrizio.montecucco@unige.it (F.M.); thschindler@wustl.edu (T.H.S.) \\ * Correspondence: filippo.molica@unige.ch
}

Received: 12 December 2019; Accepted: 26 January 2020; Published: 31 January 2020

\begin{abstract}
Endothelial dysfunction worsens when body mass index (BMI) increases. Pannexin1 (Panx1) ATP release channels regulate endothelial function and lipid homeostasis in mice. We investigated whether the Panx1-400A $>C$ single nucleotide polymorphism (SNP), encoding for a gain-of-function channel, associates with endothelial dysfunction in non-obese and obese individuals. Myocardial blood flow (MBF) was measured by ${ }^{13} \mathrm{~N}$-ammonia positron emission/computed tomography at rest, during cold pressor test (CPT) or dipyridamole-induced hyperemia. Myocardial flow reserve (MFR) and endothelial function were compared in 43 non-obese (BMI $<30 \mathrm{~kg} / \mathrm{m}^{2}$ ) vs. 29 obese $\left(\mathrm{BMI} \geq 30 \mathrm{~kg} / \mathrm{m}^{2}\right.$ ) participants and genotyping for the Panx1-400A>C SNP was performed. Groups comprised subjects homozygous for the $C$ allele $(n=40)$ vs. subjects with at least one A allele $(n=32)$. MBF (during CPT or hyperemia), MFR and endothelial function correlated negatively with BMI in the full cohort. BMI correlated negatively with MFR and endothelial function in non-obese Panx1-400C subjects, but not in Panx1-400A individuals nor in obese groups. BMI correlated positively with serum triglycerides, insulin or HOMA. MFR correlated negatively with these factors in non-obese Panx1-400C but not in Panx1-400A individuals. Here, we demonstrated that Panx1-400C SNP predisposes to BMI-dependent endothelial dysfunction in non-obese subjects. This effect may be masked by excessive dysregulation of metabolic factors in obese individuals.
\end{abstract}

Keywords: Panx1; polymorphism; endothelial function; obesity

\section{Introduction}

Endothelial dysfunction, the main cause of coronary artery disease, aggravates with increasing bodyweight and obesity [1]. A possible role for ATP in the process of endothelial dysfunction is still a matter of debate. Extracellular nucleotides, such as ATP, generally display vasculoprotective properties by regulating vasodilation through nitric oxide production [2,3]. However, ATP has also been shown to participate to the onset of endothelial dysfunction through the activation of P2X4 and P2X7 purinergic receptors [4]. In fact, prolonged exposure of endothelial cells to ATP enhances the expression of chemokines and adhesion molecules by endothelial cells [4,5]. Pannexin1 (Panx1) channels are newly discovered ATP release channels that are increasingly recognized to critically regulate vascular function [6]. Panx1 is expressed in most cells of the body, including diverse types of blood cells, endothelial and smooth muscle cells but also adipocytes [7,8]. ATP released through Panx1 channels can target surface receptors in a paracrine or autocrine fashion allowing for intercellular signaling and 
tissue homeostasis. Panx1 channels are activated under specific conditions such as mechanical stretch, elevated extracellular potassium or metabotropic (P2Y) or ionotropic (P2X) receptor activation, resulting in the elevation of intracellular calcium. Studies performed in mice have revealed a key role for Panx1 channels in the regulation of endothelial function as well as for lipid homeostasis. Thus, Panx1 has been shown to facilitate endothelium-dependent vasodilation in large arteries [9]. During acute inflammation, Panx1 channels in the endothelium promote leukocyte adhesion and emigration through the vascular wall $[10,11]$. Moreover, Panx1 deficiency has been shown to be associated with atherosclerosis and white adipose tissue accumulation as well as with lymphatic dysfunction [12]. In mice, Panx1 appeared to control adipose stromal cell proliferation and differentiation, thereby regulating fat accumulation in vivo [13]. Interestingly, a Panx1-400A >C single nucleotide polymorphism (SNP; rs1138800), inducing an amino acid change from a Glutamine to a Histidine $(\mathrm{Q} 5 \mathrm{H})$ in the N-terminus of Panx1, encodes for a gain-of-function channel [14]. The Panx1-400C genetic variant, encoding for the gain-of-function channel, specifically enhanced collagen-induced ATP release and platelet aggregation [14]. Although multiple studies in mice point to a role for Panx1 in vascular pathologies caused by impaired endothelial function, whether the Panx1-400A >C SNP associates with endothelial dysfunction in humans is presently unknown.

\section{Materials and Methods}

\subsection{Study Population}

Study participants have been recruited at the Geneva University Hospitals by flyers and newspaper advertisements. The study was approved by the institutional review board of the Geneva University Hospitals (No. 07-183) [15,16]. Each participant signed an approved informed consent form. Study participants underwent an initial screening visit comprising physical examination, electrocardiogram, blood pressure measurements and routine blood chemistry in a fasting state. Then, they underwent ${ }^{13} \mathrm{~N}$-ammonia positron emission tomography (PET)/computed tomography (CT) [17] measurements of myocardial blood flow (MBF) at rest and during vasomotor stress performed in a fasting state to assess coronary circulatory function.

Physical examination revealed normal findings in all applicants and resting electrocardiograms showed also no abnormalities. Inclusion criteria were absence of arterial hypertension (blood pressure $\leq 140 / 90 \mathrm{mmHg}$ ) or diabetes mellitus (fasting plasma glucose obtained on more than two occasions $\leq$ $126 \mathrm{mg} / \mathrm{dL}$ ), a non-smoker status and a normal stress-rest perfusion imaging on ${ }^{13} \mathrm{~N}$-ammonia PET/CT, which widely excluded the presence of flow limiting coronary artery disease lesions. The exclusion criteria were any cardiac or vasoactive medication, a history of variant angina, a family history of premature coronary artery disease, or clinically manifested cardiovascular or systemic diseases.

Recruited volunteers had a body mass index (BMI, $\mathrm{kg} / \mathrm{m}^{2}$ ) between 20.4 and 51.1. According to subject's BMI, two groups of participants were defined as 1) Non-obese group: 43 non-obese individuals with $\mathrm{BMI}<30 \mathrm{~kg} / \mathrm{m}^{2}$, and 2) Obese group: 29 individuals with $\mathrm{BMI} \geq 30 \mathrm{~kg} / \mathrm{m}^{2}$.

\subsection{Blood Measurements}

Blood chemistry included plasma triglycerides, total cholesterol, high-density lipoproteins (HDL), low-density lipoproteins (LDL), glucose, hemoglobin A1c (HbA1c), insulin and high-sensitive C-reactive protein (CRP) concentrations, as previously reported $[15,16]$. Assessment of insulin resistance using the homeostasis model assessment $(\mathrm{HOMA})$ was calculated as fasting insulin $(\mathrm{mIU} / \mathrm{L}) \times$ fasting glucose $(\mathrm{mg} / \mathrm{dL}) / 22.5$, as previously described [17].

\subsection{Assessment of Myocardial Perfusion with PET/CT}

Myocardial perfusion was determined by ${ }^{13} \mathrm{~N}$-ammonia PET/CT as previously described [17]. Myocardial blood flow (MBF, mL/g/min) was assessed at rest, during a cold pressor test (CPT), and during hyperemia pharmacologically induced with standard infusion of dipyridamole (140 mg/kg/min). 
The endothelial function was defined as $\triangle \mathrm{MBF}$ to CPT from rest, and the myocardial flow reserve (MFR) was defined as the ratio between MBF during hyperemia and MBF at rest, as previously described [16].

\subsection{Phenotype-Genotype Association Studies}

Polymerase chain reaction (PCR) for the Panx1-400A $>$ C SNP was performed on DNA isolated from the blood of each study participant with the following primers (5'-to-3'): forward CCGGTGACTGGGTGAAGG, reverse GTCCTGGGCGAGGCTTAC, as previously described [14]. Sequencing of PCR products was performed at Fasteris (Geneva, Switzerland). To identify the Panx1 genotype, all sequences comprising parts of the Panx1 coding region were analyzed using the multiple sequence alignment program ClustalW and allele frequency was calculated (i.e., minor allele frequency $=(W M+2 \times M M) /((W W+W M+M M) \times 2))$. Minor allele frequency was in accordance to the one obtained in an earlier study investigating Panx1-400A $>$ C SNP [14] and the distribution of participants of each genotype was in the Hardy-Weinberg equilibrium. Similar to earlier studies [14,18], groups were divided in subjects homozygous for the C allele (Panx1-400C, $n=40$ ) vs. subjects with at least one A allele (Panx1-400A, $n=32)$.

\subsection{Statistical Analysis}

In tables, results are shown as mean \pm standard error of the mean (SEM) or as median (interquartile range). Comparisons of means were performed using ANOVA test and post-hoc Sidak's multiple comparison test. Comparisons of medians were performed using non-parametric Kruskal-Wallis test and post-hoc Dunn's multiple comparison test. Comparisons of distributions were performed using $\chi^{2}$ test. In figures, results are shown as individual values and as correlation. Spearman correlations were performed to examine association between variables. Differences were considered statistically significant at values of $p<0.05$. Statistical analyses were performed using Graphpad Prism 8 software (GraphPad Software, Inc., San Diego, CA, USA).

\section{Results}

\subsection{BMI Correlates with Cardiovascular Risk Factors}

The clinical characteristics and laboratory measurements among the groups studied are shown in Table 1. Spearman correlations showed that in the full cohort BMI was positively correlated with cardiovascular risk factors known to be predictors of CPT-induced $\triangle \mathrm{MBF}$ and hyperemic MBF during dipyridamole stimulation [15] such as serum triglycerides (Figure 1a), glucose (Figure 1b), insulin (Figure 1c), HbA1c (Figure 1d) and CRP (Figure 1e). BMI was also positively correlated with HOMA as shown in Figure 1f. As expected, BMI was negatively correlated with the serum HDL concentration (Figure 1g). There was no correlation between BMI and total cholesterol (Figure 1h) or LDL (Figure 1i) serum levels. These results show that, in our cohort of 72 participants, increased BMI correlates with cardiovascular risk factors, which is in accordance with previously published studies [19-21].

Table 1. Patient characteristics at the time of the inclusion in the study.

\begin{tabular}{ccccc}
\hline & $\begin{array}{c}\text { Full Cohort } \\
(\boldsymbol{n}=\mathbf{7 2})\end{array}$ & $\begin{array}{c}\text { Panx1-400C } \\
\text { Cohort } \\
(\boldsymbol{n}=\mathbf{4 0})\end{array}$ & $\begin{array}{c}\text { Panx1-400A } \\
\text { Cohort } \\
(\boldsymbol{n}=\mathbf{3 2})\end{array}$ & $\boldsymbol{p}$-Value \\
\hline Age, years, mean \pm SEM & $43 \pm 1$ & $45 \pm 2$ & $42 \pm 2$ & 0.63 \\
Female/male, $n$ (\%) & $19(26) / 53(74)$ & $10(25) / 30(75)$ & $9(28) / 23(72)$ & 0.89 \\
Weight (kg), mean \pm SEM & $90 \pm 3$ & $88 \pm 3$ & $93 \pm 5$ & 0.58 \\
Height (cm), mean \pm SEM & $173 \pm 1$ & $173 \pm 1$ & $173 \pm 2$ & 0.98 \\
BMI (kg/m $)$, mean \pm SEM & $30 \pm 1$ & $45 \pm 2$ & $31 \pm 1$ & 0.58 \\
Heart rate at rest (b.p.m.),median (IQR) & $63(56-70)$ & $63(55-70)$ & $64(58-70)$ & 0.97 \\
SBP at rest (b.p.m.),median (IQR) & $119(110-129)$ & $118(106-126)$ & $120(112-132)$ & 0.28 \\
DBP at rest (b.p.m.),median (IQR) & $74(68-80)$ & $73(67-80)$ & $76(68-83)$ & 0.75 \\
\hline
\end{tabular}

BMI: body mass index; b.p.m: beat per minute; DBP: diastolic blood pressure; IQR: interquartile range; SBP: systolic blood pressure; SEM: standard error of the mean. 
(a)

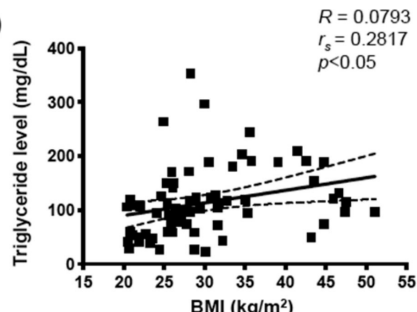

(d)

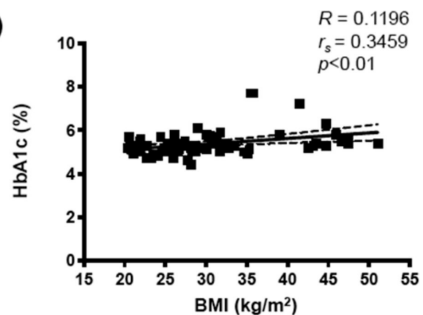

(g)

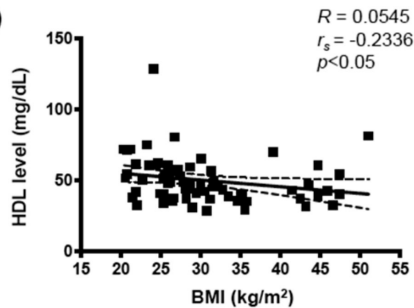

(b)

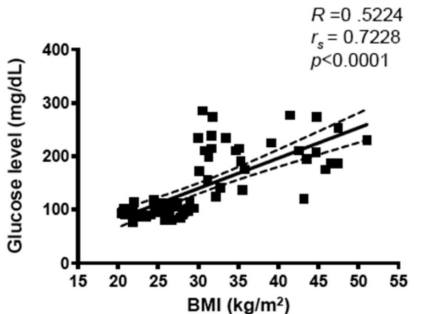

(e)

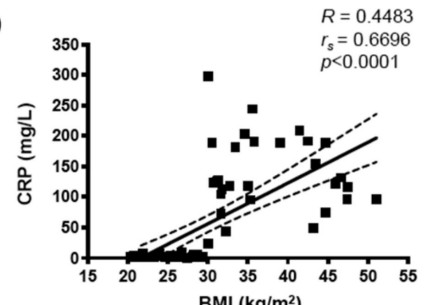

(h)

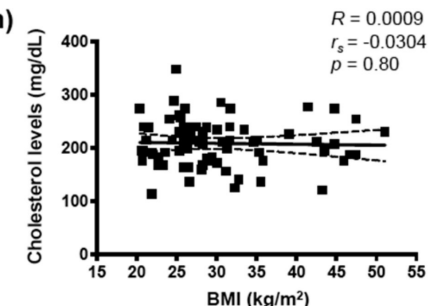

(c)

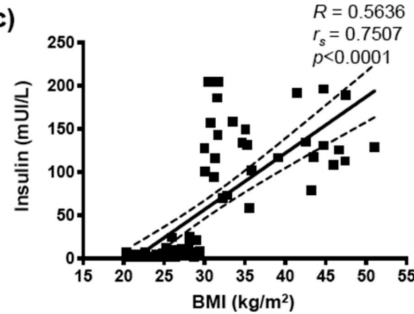

(f)

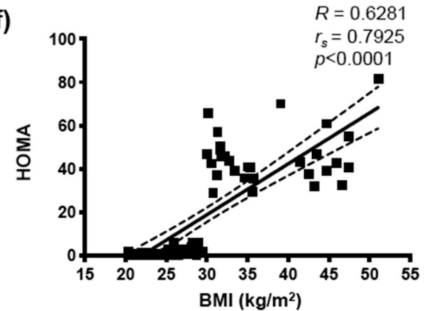

(i)

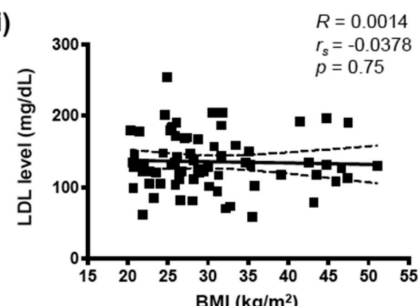

Figure 1. Body mass index (BMI) associates with cardiovascular risk factors. Spearman correlations between BMI and serum triglycerides (a), glucose (b), insulin (c), hemoglobin A1c (HbA1c, (d)), C-reactive protein (CRP, (e)), homeostasis model assessment (HOMA) (f), high density-lipoproteins $(\mathrm{HDL}, \mathrm{g})$, total cholesterol (h), and low-density lipoproteins (LDL) (i), in the full cohort of participants $(n=72)$.

\subsection{BMI, Hemodynamic Parameters, and Panx1-400A>C SNP}

When analyzed separately, the three cohorts did not show differences in the age and the proportion of females/males (Table 1). In addition, no differences were found for the height, the weight and the BMI (Table 1). Moreover, heart rate, systolic and diastolic blood pressure values at rest were not different in the three cohorts (Table 1). Whereas MBF at rest was not affected by BMI (data not shown), MBF during CPT, MBF during hyperemia, MFR, and endothelial function were negatively correlated with BMI in the full cohort (Figure 2a,d,g,j, respectively). Mean values of all these parameters were not different between the full, the Panx1-400C and the Panx1-400A cohorts (Table 2). In the Panx1-400C cohort, MBF during CTP (Figure 2b), MBF during hyperemia (Figure 2e), MFR (Figure 2h) and endothelial function (Figure 2k) were also negatively correlated with BMI whereas no correlation between these hemodynamic parameters and BMI was found in the Panx1-400A cohort (Figure 2c,f,i,l).

Table 2. MBF, MFR, and endothelial function measured during ${ }^{13} \mathrm{~N}$-ammonia PET/CT in the three cohorts.

\begin{tabular}{ccccc}
\hline & $\begin{array}{c}\text { Full Cohort } \\
(\boldsymbol{n}=\mathbf{7 2})\end{array}$ & $\begin{array}{c}\text { Panx1-400C } \\
\text { Cohort } \\
(\boldsymbol{n}=\mathbf{4 0 )}\end{array}$ & $\begin{array}{c}\text { Panx1-400A } \\
\text { Cohort } \\
(\boldsymbol{n}=\mathbf{3 2})\end{array}$ & $\boldsymbol{p}$-Value \\
\hline MBF at rest (mL/g/min), median (IQR) & $0.72(0.62-0.78)$ & $0.72(0.63-0.76)$ & $0.72(0.62-0.79)$ & 0.99 \\
MBF during CPT (mL/g/min), median (IQR) & $0.85(0.76-1.04)$ & $0.90(0.75-1.04)$ & $0.84(0.76-1.05)$ & 0.99 \\
MBF during hyperemia (mL/g/min), median (IQR) & $2.11(1.79-2.42)$ & $2.15(1.84-2.44)$ & $2.08(1.71-2.32)$ & 0.59 \\
MFR, median (IQR) & $3.03(2.41-3.43)$ & $3.28(2.52-3.50)$ & $2.76(2.38-3.31)$ & 0.40 \\
$\Delta$ MBF to CPT from rest (mL/g/min), mean \pm SEM & $0.186 \pm 0.020$ & $0.179 \pm 0.026$ & $0.194 \pm 0.030$ & 0.93 \\
\hline
\end{tabular}

CPT: cold pressor test; CT: computed tomography; IQR: interquartile range; MBF: myocardial blood flow; MFR: myocardial flow reserve; $\triangle \mathrm{MBF}$ to $\mathrm{CPT}$ from rest: endothelial function; PET: positron emission tomography; SEM: standard error of the mean. 
Full cohort

(a)

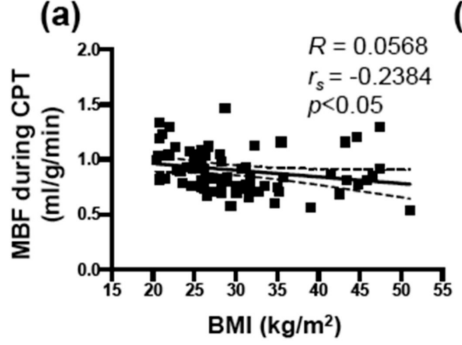

(d)

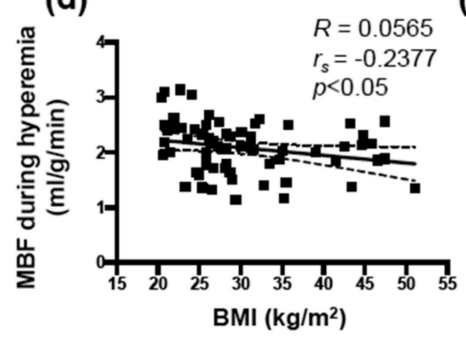

(g)

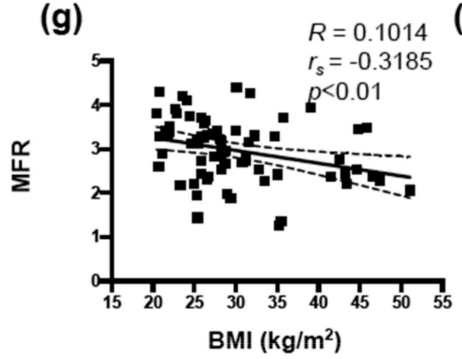

Pan $\times 1-400$ C cohort

(b)

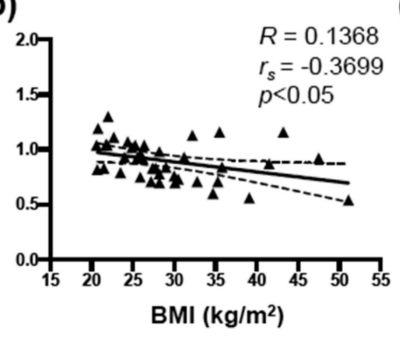

(e)

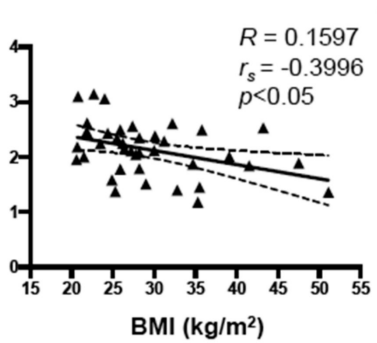

(h)

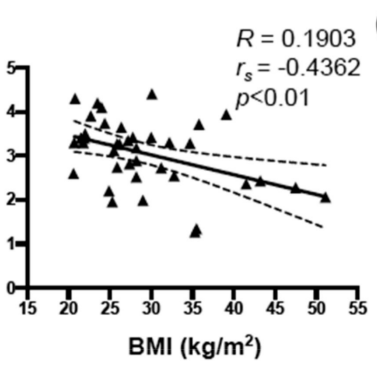

$\underline{\text { Pan } \times 1-400 \text { A cohort }}$

(c)

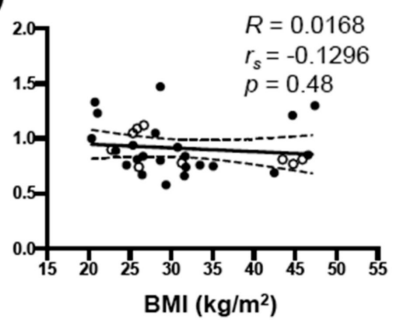

(f)

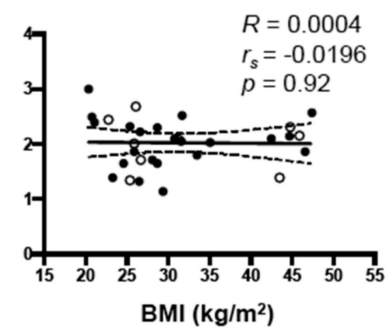

(i)

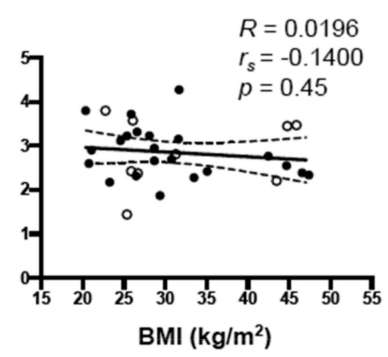

(j)

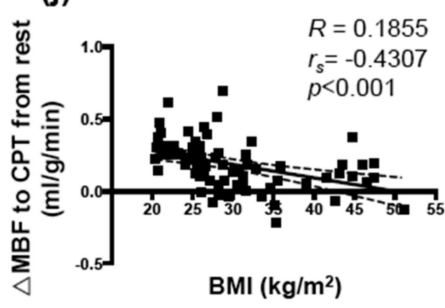

(k)

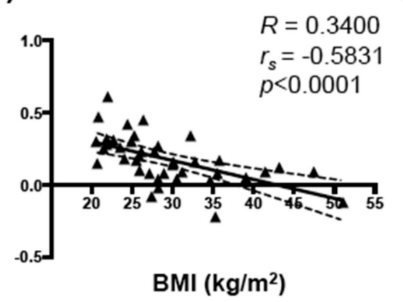

(l)

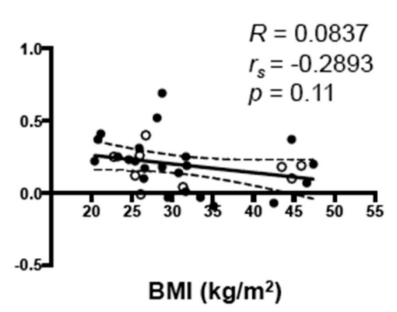

Figure 2. BMI, hemodynamic parameters and Panx1-400A $>$ C SNP. Spearman correlations between body mass index (BMI) and myocardial blood flow (MBF) during cold pressor test (CTP) (a-c), MBF during hyperemia (d-f), myocardial flow reserve (MFR) $(\mathbf{g}-\mathbf{i})$ and endothelial function $(\triangle \mathrm{MBF}$ to $\mathrm{CPT}$ from rest, $\mathbf{j}-\mathbf{1})$ in the full cohort $((\mathbf{a}, \mathbf{d}, \mathbf{g}, \mathbf{j}) n=72)$, the Panx1-400C cohort $(\mathbf{b}, \mathbf{e}, \mathbf{h}, \mathbf{k}) n=40)$ and the Panx1-400A cohort $(\mathbf{c}, \mathbf{f}, \mathbf{i}, \mathbf{l}) n=32)$. AA genotype: open circles; AC genotype: closed circles.

$\mathrm{MBF}$ at rest, MBF during hyperemia and MFR were not different between non-obese (BMI < $\left.30 \mathrm{~kg} / \mathrm{m}^{2}\right)$ and obese (BMI $\geq 30 \mathrm{~kg} / \mathrm{m}^{2}$ ) subjects in the three cohorts and were not affected by the Panx1-400A $>$ C SNP (Table 3). During CPT, MBF was reduced in obese subjects in comparison to non-obese individuals in the full cohort (Table 3). A similar trend was observed in the Panx1-400C cohort but not in the Panx1-400A cohort (Table 3). Mean endothelial function was reduced in obese individuals in comparison to non-obese subjects in all three cohorts (Table 3). 
Table 3. MBF, MFR, and endothelial function measured during ${ }^{13} \mathrm{~N}$-ammonia PET/CT in non-obese and obese subjects from the three cohorts.

\begin{tabular}{|c|c|c|c|c|c|c|c|c|c|}
\hline & $\begin{array}{l}\text { Full Cohort } \\
\text { Non-Obese } \\
\quad(n=43)\end{array}$ & $\begin{array}{c}\text { Full Cohort } \\
\text { Obese } \\
(n=29)\end{array}$ & $p$-Value & $\begin{array}{c}\text { Panx1-400C } \\
\text { Non-Obese } \\
(n=25)\end{array}$ & $\begin{array}{c}\text { Panx1-400C } \\
\text { Obese } \\
(n=15)\end{array}$ & $p$-Value & $\begin{array}{c}\text { Panx1-400A } \\
\text { Non-Obese } \\
\quad(n=18)\end{array}$ & $\begin{array}{c}\text { Panx1-400A } \\
\text { Obese } \\
(n=14)\end{array}$ & $p$-Value \\
\hline MBF at rest $(\mathrm{mL} / \mathrm{g} / \mathrm{min})$, median $(\mathrm{IQR})$ & $\begin{array}{c}0.72 \\
(0.63-0.76)\end{array}$ & $\begin{array}{c}0.74 \\
(0.62-0.84)\end{array}$ & 0.35 & $\begin{array}{c}0.72 \\
(0.65-0.75)\end{array}$ & $\begin{array}{c}0.69 \\
(0.57-0.84)\end{array}$ & 0.74 & $\begin{array}{c}0.70 \\
(0.60-0.79)\end{array}$ & $\begin{array}{c}0.75 \\
(0.63-0.80)\end{array}$ & 0.42 \\
\hline MBF during $\mathrm{CPT}(\mathrm{mL} / \mathrm{g} / \mathrm{min})$, median (IQR) & $\begin{array}{c}0.93 \\
(0.81-1.05)\end{array}$ & $\begin{array}{c}0.78 \\
(0.71-0.92)\end{array}$ & $<0.01$ & $\begin{array}{c}0.93 \\
(0.83-1.04)\end{array}$ & $\begin{array}{c}0.76 \\
(0.70-0.93)\end{array}$ & 0.06 & $\begin{array}{c}0.92 \\
(0.78-1.10)\end{array}$ & $\begin{array}{c}0.80 \\
(0.75-0.87)\end{array}$ & 0.12 \\
\hline MBF during hyperemia (mL/g/min), median (IQR) & $\begin{array}{c}2.18 \\
(1.71-2.44)\end{array}$ & $\begin{array}{c}2.08 \\
(1.84-2.31)\end{array}$ & 0.43 & $\begin{array}{c}2.24 \\
(1.98-2.47)\end{array}$ & $\begin{array}{c}1.95 \\
(1.44-2.41)\end{array}$ & 0.14 & $\begin{array}{c}1.94 \\
(1.59-2.40)\end{array}$ & $\begin{array}{c}2.10 \\
(1.95-2.23)\end{array}$ & 0.51 \\
\hline MFR, median (IQR) & $\begin{array}{c}3.22 \\
(2.6-3.5)\end{array}$ & $\begin{array}{c}2.69 \\
(2.34-3.42)\end{array}$ & 0.16 & $\begin{array}{c}3.3 \\
(2.78-3.58)\end{array}$ & $\begin{array}{c}2.64 \\
(2.22-3.49)\end{array}$ & 0.20 & $\begin{array}{c}2.92 \\
(2.36-3.38)\end{array}$ & $\begin{array}{c}2.69 \\
(2.36-3.30)\end{array}$ & 0.70 \\
\hline$\triangle \mathrm{MBF}$ to $\mathrm{CPT}$ from rest $(\mathrm{mL} / \mathrm{g} / \mathrm{min})$, mean $\pm \mathrm{SEM}$ & $0.246 \pm 0.025$ & $0.095 \pm 0.023$ & $<0.001$ & $0.238 \pm 0.032$ & $0.081 \pm 0.033$ & $<0.01$ & $0.259 \pm 0.042$ & $0.111 \pm 0.035$ & $<0.05$ \\
\hline
\end{tabular}

CPT: cold pressor test; CT: computed tomography; IQR: interquartile range; MBF: myocardial blood flow; MFR: myocardial flow reserve; $\triangle \mathrm{MBF}$ to CPT from rest: endothelial function; PET: positron emission tomography; SEM: standard error of the mean. 
In non-obese individuals, negative correlations between BMI and MFR and between BMI and endothelial function were observed in the full cohort of participants (Figure 3a,d, respectively). Interestingly, such correlations for non-obese subjects were also observed in the Panx1-400C cohort (Figure 3b,e) but not in the Panx1-400A cohort (Figure 3c,f). No correlation between BMI and MFR or between BMI and endothelial function was observed for obese subjects in the three cohorts (Figure 3).

\section{Full cohort}

(a)
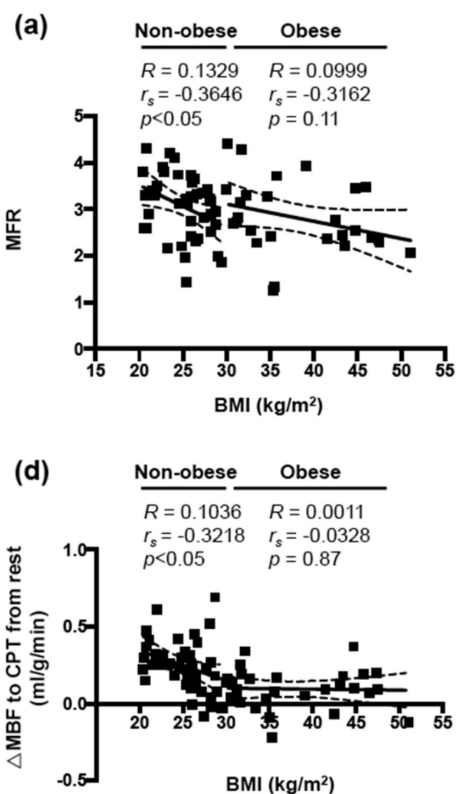

$\underline{\text { Pan } \times 1-400 C \text { cohort }}$

(b)

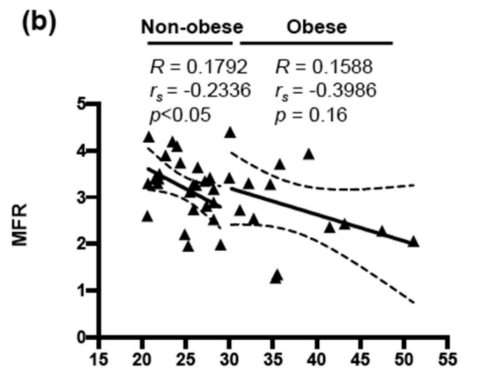

BMI $\left(\mathrm{kg} / \mathrm{m}^{2}\right)$

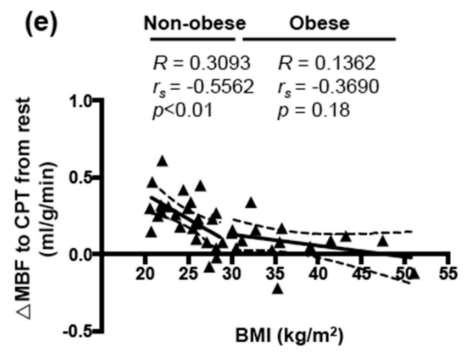

\section{$\underline{\text { Pan } \times 1-400 \text { A cohort }}$}
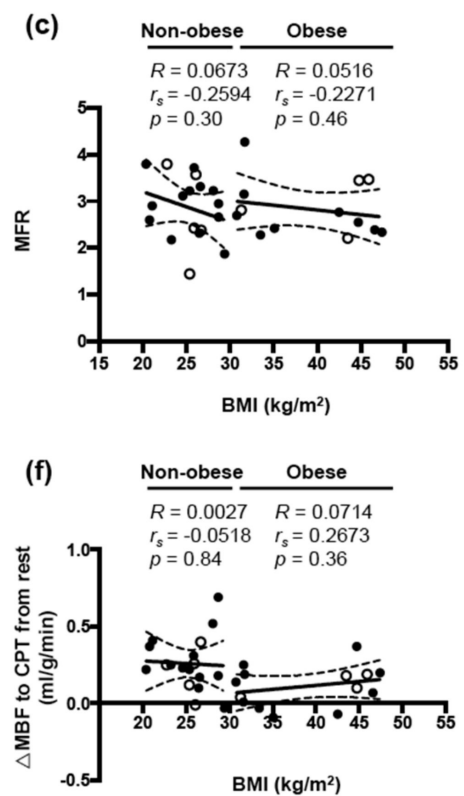

Figure 3. Correlation between BMI and MFR or endothelial function. Spearman correlations between body mass index (BMI) and myocardial flow reserve (MFR, $(\mathbf{a}-\mathbf{c}))$ or endothelial function $(\triangle \mathrm{MBF}$ to CPT from rest, (d-f)) in non-obese and obese subjects in the full cohort $((\mathbf{a}, \mathbf{d}) n=43$ and 29 , respectively), the Panx1-400C cohort ((b,e) $n=25$ and 15, respectively) and the Panx1-400A cohort $((\mathbf{c}, \mathbf{f}) n=18$ and 14, respectively). AA genotype: open circles; AC genotype: closed circles.

Altogether, these results bring out that the Panx1-400A $>$ C SNP does not change by itself hemodynamic parameters but that the impairment of these hemodynamic parameters is correlated with increased BMI in Panx1-400C subjects but not in Panx1-400A individuals. Moreover, this effect of the Panx1-400C SNP on the impairment of these hemodynamic parameters with increasing bodyweight is only present in non-obese subjects.

\subsection{Correlation between BMI and Cardiovascular Risk Factors in Non-obese and Obese Subjects}

In non-obese individuals, serum triglycerides and insulin as well as HOMA were positively correlated with increasing BMI in the Panx1-400C cohort (Figure 4a,c,e respectively), but not in the Panx1-400A cohort (Figure 4b,d,f, respectively). In both cohorts, no correlation was observed between increasing $\mathrm{BMI}$ and serum glucose, $\mathrm{HbA1c}, \mathrm{CRP}$, or HDL concentrations for non-obese subjects (data not shown). For obese subjects, no correlation was shown between increasing BMI and the various cardiovascular risk factors tested (data not shown).

Here, we show that in non-obese subjects, Panx1-400C SNP favors positive correlation between BMI and triglyceride levels, insulin levels and HOMA, which is not the case for non-obese Panx1-400A individuals. 
(a)

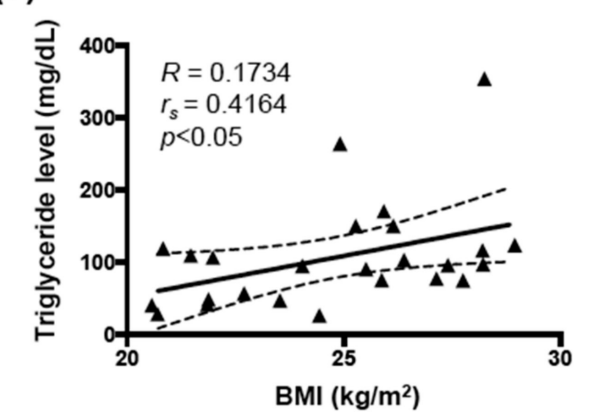

(c)

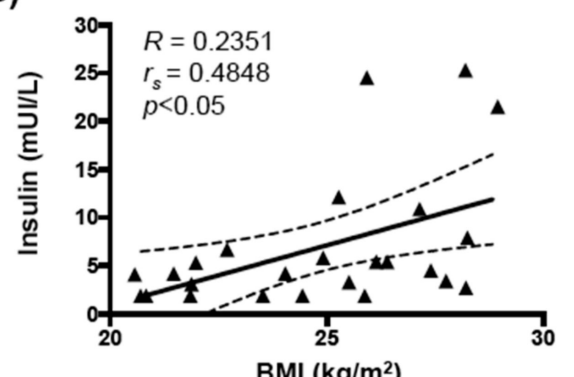

(e)

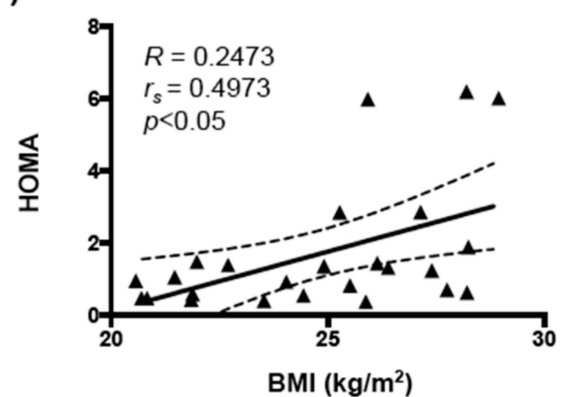

(b)

Non-obese / Panx1-400A cohort

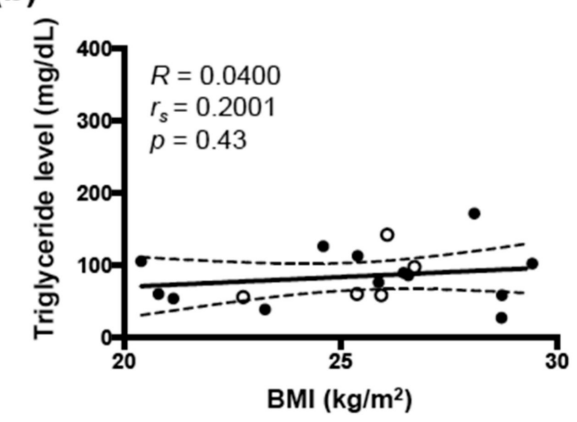

(d)

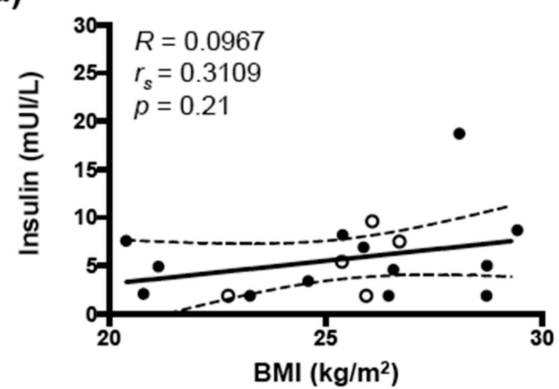

(f)

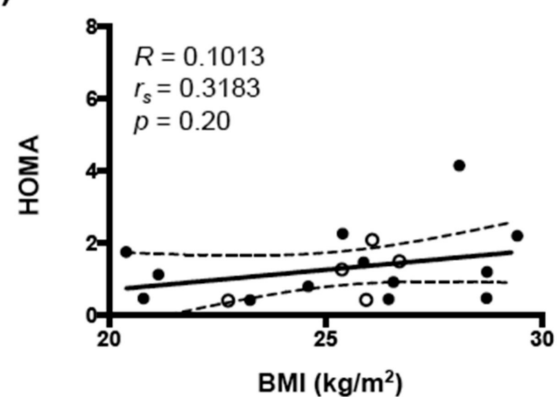

Figure 4. Correlation between BMI and cardiovascular risk factors in non-obese subjects. Spearman correlations in non-obese subjects between body mass index (BMI) and serum triglycerides $(\mathbf{a}, \mathbf{b})$, insulin $(\mathbf{c}, \mathbf{d})$ and HOMA $(\mathbf{e}, \mathbf{f})$ in the Panx1-400C cohort $((\mathbf{a}, \mathbf{c}, \mathbf{e}) n=25)$ and the Panx1-400A cohort $((\mathbf{b}, \mathbf{d}, \mathbf{f})$ $n=18)$. AA genotype: open circles; AC genotype: closed circles.

\subsection{Correlation Between Hemodynamic Parameters and Cardiovascular Risk Factors in Non-Obese Subjects}

Negative correlations between MFR and serum triglycerides, insulin or HOMA were observed in non-obese subjects from the Panx1-400C cohort (Figure 5a,c,e, respectively). These correlations were completely absent in non-obese subjects from the Panx1-400A cohort (Figure 5b,d,f). Moreover, the slopes of the correlation between MFR and these cardiovascular risk factors in non-obese individuals were significantly different between the Panx1-400C and the Panx1-400A cohorts (Figure 5a vs. Figure 5b, Figure $5 c$ vs. Figure 5d, and Figure 5e vs. Figure 5f).

Finally, no correlation was found between endothelial function and serum triglycerides (Figure 6a,b), insulin (Figure 6c,d) or HOMA (Figure 6e,f) in non-obese subjects from the Panx1-400C cohort (Figure $6 \mathrm{a}, \mathrm{c}, \mathrm{e}$ ) or the Panx1-400A cohort (Figure $6 \mathrm{~b}, \mathrm{~d}, \mathrm{f}$ ).

Altogether, our results demonstrate that for non-obese Panx1-400C subjects, elevation in triglyceride and insulin concentrations as well as increased HOMA promote endothelial dysfunction and a reduction in MFR, effects that are absent or even slightly inverted in non-obese Panx1-400A subjects. 
(a)

Non-obese / Panx1-400C cohort

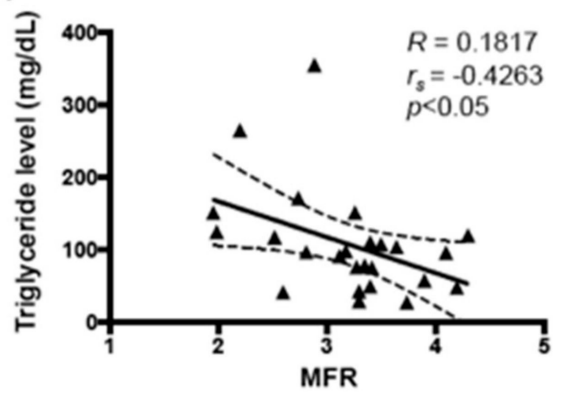

(c)

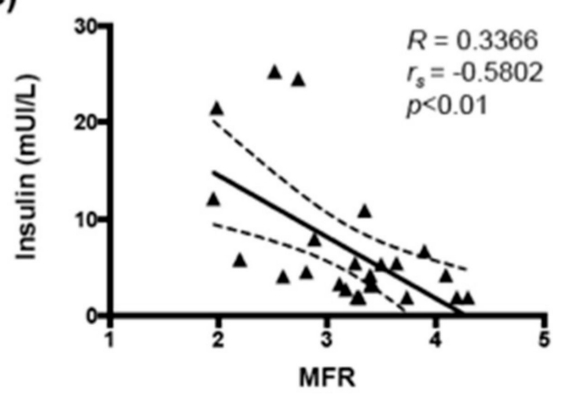

(e)

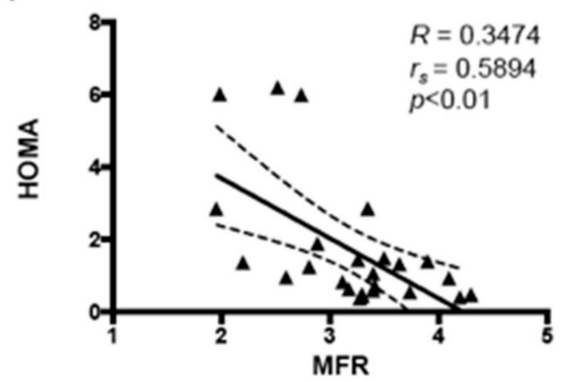

(b)

Non-obese / Panx1-400A cohort

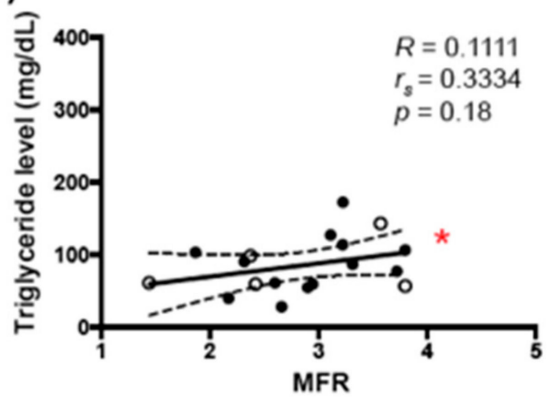

(d)

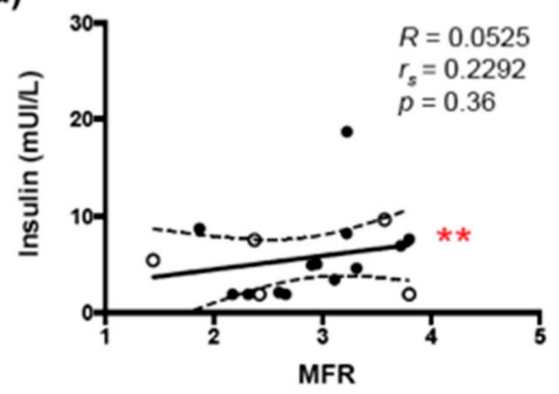

(f)

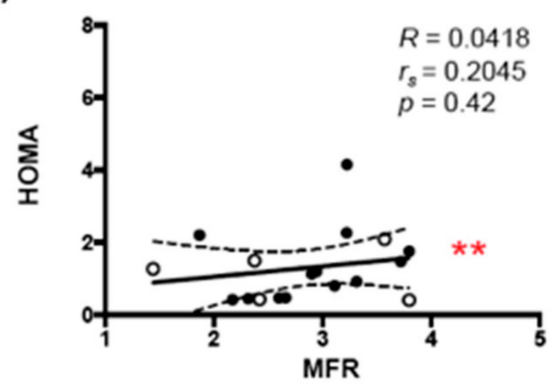

Figure 5. Correlation between MFR and cardiovascular risk factors in non-obese subjects. Spearman correlations in non-obese individuals between myocardial flow reserve (MFR) and serum triglycerides $(\mathbf{a}, \mathbf{b})$, insulin $(\mathbf{c}, \mathbf{d})$, and HOMA $(\mathbf{e}, \mathbf{f})$ in the Panx1-400C cohort $((\mathbf{a}, \mathbf{c}, \mathbf{e}) n=25)$ and the Panx1-400A cohort $((\mathbf{b}, \mathbf{d}, \mathbf{f}) n=18)$. AA genotype: open circles; AC genotype: closed circles. ${ }^{*} p<0.05 ;{ }^{* *} p<0.01$ : slope of non-obese subjects in the Panx1-400C cohort vs. slope of non-obese subjects in the Panx1-400A cohort. 
(a)

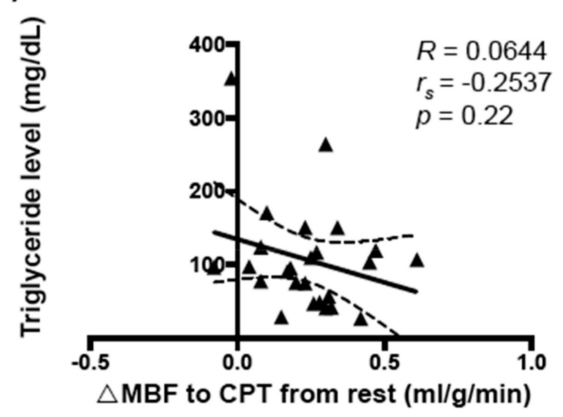

(c)

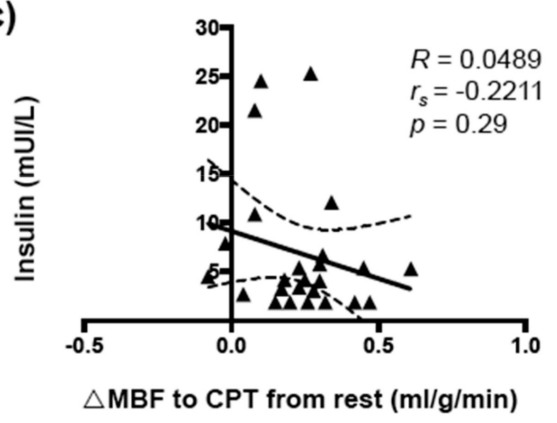

(e)

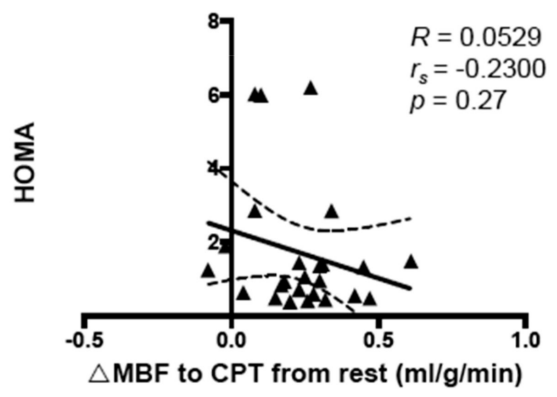

(b)

Non-obese / Panx1-400A cohort

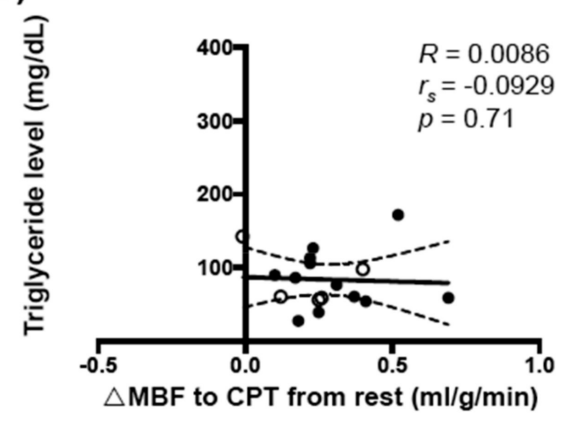

(d)

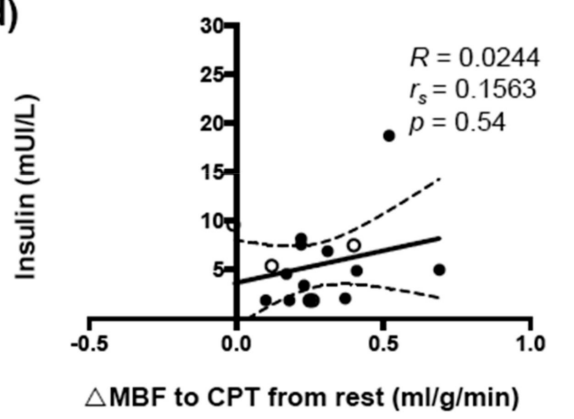

(f)

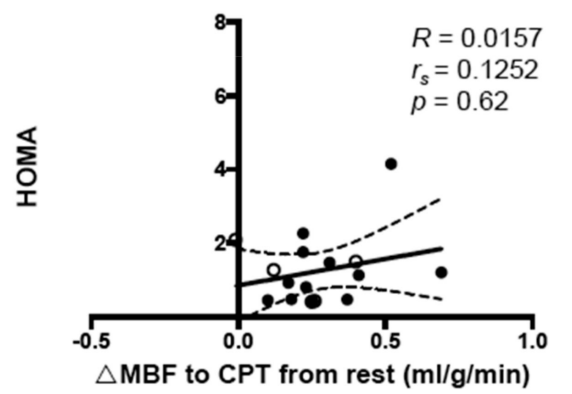

Figure 6. Correlation between endothelial function and cardiovascular risk factors in non-obese subjects. Spearman correlations in non-obese subjects between endothelial function and serum triglycerides $(\mathbf{a}, \mathbf{b})$, insulin $(\mathbf{c}, \mathbf{d})$, and HOMA $(\mathbf{e}, \mathbf{f})$ in the Panx1-400C cohort $((\mathbf{a}, \mathbf{c}, \mathbf{e}) n=25)$ and the Panx1-400A cohort $((\mathbf{b}, \mathbf{d}, \mathbf{f}) n=18)$. AA genotype: open circles; AC genotype: closed circles.

\section{Discussion}

The present study shows for the first time an implication of the Panx1-A400C SNP in endothelial dysfunction and reduced myocardial perfusion under stress. Panx1 channels are involved in physiological and pathological processes ascribed to ATP release such as the regulation of vasomotor function, glucose metabolism, leukocyte recruitment, adipogenic progenitor cell differentiation, ischemia-reperfusion injury or pain [22-29]. This multiplicity of functions involves different mechanisms of Panx1 channel activation including elevated extracellular potassium, stretch, Src family kinase-mediated phosphorylation, or cleavage of the C-terminal tail by caspases [8]. The SNP studied in the present study has been demonstrated to affect Panx1 channel functionality [14]. The base pair modification A400C in the Panx1 gene results in an amino acid substitution at position 5 in the cytoplasmic N-terminal part of the protein. This shift from an uncharged Glutamine to a positively charged Histidine may induce conformational changes in the pore formed by the hexameric assembly of Panx1 proteins, leading to enhanced ATP release. Indeed, Panx1-deficient $\mathrm{CHO}$ cells transfected with Panx1-400C displayed increased basal and stimulated ATP release compared to cells transfected 
with Panx1-400A [14]. The effects of other N-terminal modifications on Panx1 channel opening have been demonstrated by patch clamp experiments showing that a weak voltage-dependent activity is drastically increased when a Glycine-Serine amino acid pair is inserted after the first Methionine [30].

The Panx1-A400C SNP has previously been described as potential modifier of atherothrombosis [14]. Indeed, the gain-of-function channel variant (Panx1-400C) was associated with enhanced collagen-induced platelet reactivity in a cohort of 96 healthy volunteers and was also identified in cohorts of patients with a hyper- or hypo-reactive platelet phenotype with the Panx1-400C variant being more prevalent in the hyper-reactive patients. Here, we aimed to evaluate the potential implication of this Panx1 genetic variant in endothelial dysfunction and myocardial perfusion in obese and non-obese individuals. Overweight and obesity are conditions known to alter endothelial cell functionality [1] through mechanisms such as insulin resistance, increased serum cholesterol and LDL levels, pro-inflammatory adipokine release and elevated free fatty acids (FFAs) production by adipose tissue [31]. In accordance, we showed in our full cohort of 72 study participants that increased BMI was positively correlated with serum triglycerides, glucose, insulin, HbA1c and CRP levels, and with insulin resistance (HOMA) (Figure 1). Moreover, increased BMI was negatively correlated with myocardial perfusion under stress and with endothelial function (Figure 2). These negative correlations were also found in a subgroup of non-obese individuals but were lost in obese subjects (Figure 3). Interestingly, similar negative correlations were observed in Panx1-400C subjects but not in Panx1-400A individuals (Figures 2 and 3). In Panx1-400C non-obese subjects, BMI was positively correlated with triglycerides and insulin levels and with HOMA (Figure 4). Such positive correlations were absent in Panx1-400A non-obese individuals. Elevated triglyceride levels as well as increased glucose and insulin concentrations are known to induce endothelial dysfunction by increasing inflammation, apoptosis, and mainly by increasing reactive oxygen species production [32-34]. The latter processes have all three been shown to be affected by Panx1 expression or Panx1 channel functionality. For instance, in atherosclerosis-prone mice fed a high cholesterol diet, ubiquitous Panx1 deletion was shown to reduce serum triglyceride and FFA levels [12]. This effect was attributed to impairment of lymphatic function in Panx1-deficient mice, which is affecting lipid uptake as demonstrated with an oral lipid tolerance test. Moreover, experiments performed in rat INS-1E beta-cells showed that Panx1 channel activation by chronic fructose exposure potentiated glucose-stimulated insulin secretion [29]. In addition, Panx1 channel activity appeared to contribute to the control of metabolic homeostasis by regulating insulin-stimulated glucose uptake in adipocytes [24]. Finally, mice with ubiquitous Panx1 deletion have increased fat mass and reduced lean mass [12,13]. This increase in body adiposity is mainly due to larger volumes of subcutaneous and visceral adipose tissues [12] and results in increased glucose and insulin levels [13]. Altogether, these observations suggest strong links between Panx1 channel functionality, metabolism and endothelial function. Our data further strengthen this hypothesis as we found that myocardial perfusion under stress was negatively correlated with BMI (Figure 3), serum triglycerides, insulin levels and HOMA (Figure 5) in Panx1-400C non-obese subjects expressing the gain-of-function channel, while no correlation between these parameters was found in the non-obese Panx1-400A cohort. The reason that the effect of the gain-of-function channel is lost in obese subjects might be an exacerbated increase in metabolic and cardiovascular risk factors in this sub-population. Altogether, these results suggest that the Panx1-A400C SNP by itself does not influence hemodynamic parameters, but that the impairment of hemodynamic function is correlated with increased BMI in Panx1-400C subjects but not in Panx1-400A individuals. Many studies indicate that the risk to develop endothelial dysfunction increases with the number of risk factors co-existing in an individual $[35,36]$. This association between increased BMI and reduced MFR in the non-obese subjects of the Panx1-400C cohort could be attributed to increased risk factors for endothelial dysfunction. Although no significant correlation between endothelial function and serum triglycerides, insulin and HOMA were observed in Panx1-400C individuals, it is noteworthy that a similar trend to the one obtained for myocardial perfusion under stress was found (Figure 6). Although the main limitation of the present study is the small size of the cohorts, to the best of our knowledge, this study is the first one uniquely linking the Panx1 SNP, encoding for a gain-of-function ATP release channel, BMI, cardiovascular risk 
factors, endothelial function and myocardial perfusion. The prevalent Panx1-400C SNP thus drives the relation between impaired hemodynamic parameters, increased occurrence of cardiovascular risk factors and increased BMI in the general population, which may be taken into account in future investigations.

\section{Conclusions}

Our data show that the Panx1-400C SNP predisposes for the development of endothelial dysfunction and reduced myocardial perfusion during stress (induced by CPT or dipyridamole-induced hyperemia) with increasing BMI in non-obese subjects.

Author Contributions: Conceptualization, F.M. (Filippo Molica), B.R.K., and S.M.; methodology, A.Q. and F.M. (Filippo Molica); formal analysis, A.Q., F.M. (Filippo Molica) and S.M.; resources, T.H.S. and B.R.K.; data curation, A.Q., F.M. (Fabrizio Montecucco) and S.M.; writing-original draft preparation, F.M. (Filippo Molica) and S.M.; writing-review and editing, A.Q., F.M. (Fabrizio Montecucco), T.H.S. and B.R.K.; supervision, T.H.S. and B.R.K.; project administration, T.H.S. and B.R.K.; funding acquisition, T.H.S. and B.R.K. All authors have read and agreed to the published version of the manuscript.

Funding: This research was funded by grants from the Swiss National Science Foundation [310030_182573 to B.R. Kwak and 3200B0_122237 to Thomas H. Schindler].

Acknowledgments: The authors thank all volunteers for participating to the study. They also would like to thank Bernard Foglia and Merlijn Meens for technical assistance and helpful discussions.

Conflicts of Interest: The authors declare no conflict of interest. The funders had no role in the design of the study; in the collection, analyses, or interpretation of data; in the writing of the manuscript, or in the decision to publish the results.

\section{References}

1. Silver, A.E.; Beske, S.D.; Christou, D.D.; Donato, A.J.; Moreau, K.L.; Eskurza, I.; Gates, P.E.; Seals, D.R. Overweight and obese humans demonstrate increased vascular endothelial NAD(P)H oxidase-p47(phox) expression and evidence of endothelial oxidative stress. Circulation 2007, 115, 627-637. [CrossRef]

2. Guns, P.J.; Van Assche, T.; Fransen, P.; Robaye, B.; Boeynaems, J.M.; Bult, H. Endothelium-dependent relaxation evoked by ATP and UTP in the aorta of P2Y2-deficient mice. Br. J. Pharmacol. 2006, 147, 569-574. [CrossRef] [PubMed]

3. Da Silva, C.G.; Specht, A.; Wegiel, B.; Ferran, C.; Kaczmarek, E. Mechanism of purinergic activation of endothelial nitric oxide synthase in endothelial cells. Circulation 2009, 119, 871-879. [CrossRef] [PubMed]

4. Sathanoori, R.; Sward, K.; Olde, B.; Erlinge, D. The ATP receptors P2X7 and P2X4 modulate high glucose and palmitate-induced inflammatory responses in endothelial cells. PLOS ONE 2015, 10, e0125111.

5. Stachon, P.; Geis, S.; Peikert, A.; Heidenreich, A.; Michel, N.A.; Unal, F.; Hoppe, N.; Dufner, B.; Schulte, L.; Marchini, T.; et al. Extracellular ATP induces vascular inflammation and atherosclerosis via purinergic receptor Y2 in mice. Arterioscler. Thromb. Vasc. Biol. 2016, 36, 1577-1586. [CrossRef]

6. Molica, F.; Figueroa, X.F.; Kwak, B.R.; Isakson, B.E.; Gibbins, J.M. Connexins and pannexins in vascular function and disease. Int. J. Mol. Sci. 2018, 19, 1663. [CrossRef]

7. Penuela, S.; Harland, L.; Simek, J.; Laird, D.W. Pannexin channels and their links to human disease. Biochem. J. 2014, 461, 371-381. [CrossRef]

8. Chiu, Y.H.; Schappe, M.S.; Desai, B.N.; Bayliss, D.A. Revisiting multimodal activation and channel properties of pannexin 1. J. Gen. Physiol. 2018, 150, 19-39. [CrossRef]

9. Gaynullina, D.; Shestopalov, V.I.; Panchin, Y.; Tarasova, O.S. Pannexin 1 facilitates arterial relaxation via an endothelium-derived hyperpolarization mechanism. FEBS Lett. 2015, 589, 1164-1170. [CrossRef]

10. Lohman, A.W.; Leskov, I.L.; Butcher, J.T.; Johnstone, S.R.; Stokes, T.A.; Begandt, D.; DeLalio, L.J.; Best, A.K.; Penuela, S.; Leitinger, N.; et al. Pannexin 1 channels regulate leukocyte emigration through the venous endothelium during acute inflammation. Nat. Commun. 2015, 6, 7965. [CrossRef]

11. Sharma, A.K.; Charles, E.J.; Zhao, Y.; Narahari, A.K.; Baderdinni, P.K.; Good, M.E.; Lorenz, U.M.; Kron, I.L.; Bayliss, D.A.; Ravichandran, K.S.; et al. Pannexin-1 channels on endothelial cells mediate vascular inflammation during lung ischemia-reperfusion injury. Am. J. Physiol. Lung. Cell Mol Physiol. 2018, 315, L301-L312. [CrossRef] [PubMed] 
12. Molica, F.; Meens, M.J.; Dubrot, J.; Ehrlich, A.; Roth, C.L.; Morel, S.; Pelli, G.; Vinet, L.; Braunersreuther, V.; Ratib, O.; et al. Pannexin1 links lymphatic function to lipid metabolism and atherosclerosis. Sci. Rep. 2017, 7, 13706. [CrossRef] [PubMed]

13. Lee, V.R.; Barr, K.J.; Kelly, J.J.; Johnston, D.; Brown, C.F.C.; Robb, K.P.; Sayedyahossein, S.; Huang, K.; Gros, R.; Flynn, L.E.; et al. Pannexin 1 regulates adipose stromal cell differentiation and fat accumulation. Sci. Rep. 2018, 8, 16166. [CrossRef] [PubMed]

14. Molica, F.; Morel, S.; Meens, M.J.; Denis, J.F.; Bradfield, P.F.; Penuela, S.; Zufferey, A.; Monyer, H.; Imhof, B.A.; Chanson, M.; et al. Functional role of a polymorphism in the pannexin1 gene in collagen-induced platelet aggregation. Thromb. Haemost. 2015, 114, 325-336. [CrossRef] [PubMed]

15. Quercioli, A.; Pataky, Z.; Vincenti, G.; Makoundou, V.; Di Marzo, V.; Montecucco, F.; Carballo, S.; Thomas, A.; Staub, C.; Steffens, S.; et al. Elevated endocannabinoid plasma levels are associated with coronary circulatory dysfunction in obesity. Eur. Heart J. 2011, 32, 1369-1378. [CrossRef]

16. Quercioli, A.; Pataky, Z.; Montecucco, F.; Carballo, S.; Thomas, A.; Staub, C.; Di Marzo, V.; Vincenti, G.; Ambrosio, G.; Ratib, O.; et al. Coronary vasomotor control in obesity and morbid obesity: Contrasting flow responses with endocannabinoids, leptin, and inflammation. JACC Cardiovasc. Imaging 2012, 5, 805-815. [CrossRef]

17. Schindler, T.H.; Cardenas, J.; Prior, J.O.; Facta, A.D.; Kreissl, M.C.; Zhang, X.L.; Sayre, J.; Dahlbom, M.; Licinio, J.; Schelbert, H.R. Relationship between increasing body weight, insulin resistance, inflammation, adipocytokine leptin, and coronary circulatory function. J. Am. Coll. Cardiol. 2006, 47, 1188-1195. [CrossRef]

18. Stierlin, F.B.; Molica, F.; Reny, J.L.; Kwak, B.R.; Fontana, P. Pannexin1 single nucleotide polymorphism and platelet reactivity in a cohort of cardiovascular patients. Cell Commun. Adhes. 2017, 23, 11-15. [CrossRef]

19. Dandona, P.; Aljada, A.; Chaudhuri, A.; Mohanty, P.; Garg, R. Metabolic syndrome: A comprehensive perspective based on interactions between obesity, diabetes, and inflammation. Circulation 2005, 111, 1448-1454. [CrossRef]

20. Shamai, L.; Lurix, E.; Shen, M.; Novaro, G.M.; Szomstein, S.; Rosenthal, R.; Hernandez, A.V.; Asher, C.R. Association of body mass index and lipid profiles: Evaluation of a broad spectrum of body mass index patients including the morbidly obese. Obes. Surg. 2011, 21, 42-47. [CrossRef]

21. Sinaiko, A.R.; Steinberger, J.; Moran, A.; Prineas, R.J.; Vessby, B.; Basu, S.; Tracy, R.; Jacobs, D.R., Jr. Relation of body mass index and insulin resistance to cardiovascular risk factors, inflammatory factors, and oxidative stress during adolescence. Circulation 2005, 111, 1985-1991. [CrossRef] [PubMed]

22. Chekeni, F.B.; Elliott, M.R.; Sandilos, J.K.; Walk, S.F.; Kinchen, J.M.; Lazarowski, E.R.; Armstrong, A.J.; Penuela, S.; Laird, D.W.; Salvesen, G.S.; et al. Pannexin 1 channels mediate 'find-me' signal release and membrane permeability during apoptosis. Nature 2010, 467, 863-867. [CrossRef] [PubMed]

23. Bargiotas, P.; Krenz, A.; Hormuzdi, S.G.; Ridder, D.A.; Herb, A.; Barakat, W.; Penuela, S.; von Engelhardt, J.; Monyer, H.; Schwaninger, M. Pannexins in ischemia-induced neurodegeneration. Proc. Natl. Acad. Sci. USA 2011, 108, 20772-20777. [CrossRef] [PubMed]

24. Adamson, S.E.; Meher, A.K.; Chiu, Y.H.; Sandilos, J.K.; Oberholtzer, N.P.; Walker, N.N.; Hargett, S.R.; Seaman, S.A.; Peirce-Cottler, S.M.; Isakson, B.E.; et al. Pannexin 1 is required for full activation of insulin-stimulated glucose uptake in adipocytes. Mol. Metab. 2015, 4, 610-618. [CrossRef]

25. Billaud, M.; Chiu, Y.H.; Lohman, A.W.; Parpaite, T.; Butcher, J.T.; Mutchler, S.M.; DeLalio, L.J.; Artamonov, M.V.; Sandilos, J.K.; Best, A.K.; et al. A molecular signature in the pannexin1 intracellular loop confers channel activation by the alpha1 adrenoreceptor in smooth muscle cells. Sci. Signal 2015, 8, ra17. [CrossRef]

26. Weilinger, N.L.; Lohman, A.W.; Rakai, B.D.; Ma, E.M.; Bialecki, J.; Maslieieva, V.; Rilea, T.; Bandet, M.V.; Ikuta, N.T.; Scott, L.; et al. Metabotropic nmda receptor signaling couples src family kinases to pannexin-1 during excitotoxicity. Nat. Neurosci. 2016, 19, 432-442. [CrossRef]

27. Burma, N.E.; Bonin, R.P.; Leduc-Pessah, H.; Baimel, C.; Cairncross, Z.F.; Mousseau, M.; Shankara, J.V.; Stemkowski, P.L.; Baimoukhametova, D.; Bains, J.S.; et al. Blocking microglial pannexin-1 channels alleviates morphine withdrawal in rodents. Nat. Med. 2017, 23, 355-360. [CrossRef]

28. Weaver, J.L.; Arandjelovic, S.; Brown, G.S.K.M.M.S.S.; Buckley, M.W.; Chiu, Y.H.; Shu, S.; Kim, J.K.; Chung, J.; et al. Hematopoietic pannexin 1 function is critical for neuropathic pain. Sci. Rep. 2017, 7, 42550. [CrossRef] 
29. Bartley, C.; Brun, T.; Oberhauser, L.; Grimaldi, M.; Molica, F.; Kwak, B.R.; Bosco, D.; Chanson, M.; Maechler, P. Chronic fructose renders pancreatic beta-cells hyper-responsive to glucose-stimulated insulin secretion through extracellular atp signaling. Am. J. Physiol. Endocrinol. Metab. 2019, 317, E25-E41. [CrossRef]

30. Michalski, K.; Henze, E.; Nguyen, P.; Lynch, P.; Kawate, T. The weak voltage dependence of pannexin 1 channels can be tuned by n-terminal modifications. J. Gen. Physiol. 2018, 150, 1758-1768. [CrossRef]

31. Prieto, D.; Contreras, C.; Sanchez, A. Endothelial dysfunction, obesity and insulin resistance. Curr. Vasc. Pharmacol. 2014, 12, 412-426. [CrossRef] [PubMed]

32. Kajikawa, M.; Higashi, Y. Triglycerides and endothelial function: Molecular biology to clinical perspective. Curr. Opin. Lipidol. 2019, 30, 364-369. [CrossRef] [PubMed]

33. Li, Q.; Lin, Y.; Wang, S.; Zhang, L.; Guo, L. Glp-1 inhibits high-glucose-induced oxidative injury of vascular endothelial cells. Sci. Rep. 2017, 7, 8008. [CrossRef] [PubMed]

34. Symons, J.D. Opportunity "nox": A novel approach to preventing endothelial dysfunction in the context of insulin resistance. Diabetes 2013, 62, 1818-1820. [CrossRef] [PubMed]

35. Vita, J.A.; Treasure, C.B.; Nabel, E.G.; McLenachan, J.M.; Fish, R.D.; Yeung, A.C.; Vekshtein, V.I.; Selwyn, A.P.; Ganz, P. Coronary vasomotor response to acetylcholine relates to risk factors for coronary artery disease. Circulation 1990, 81, 491-497. [CrossRef] [PubMed]

36. Celermajer, D.S.; Sorensen, K.E.; Bull, C.; Robinson, J.; Deanfield, J.E. Endothelium-dependent dilation in the systemic arteries of asymptomatic subjects relates to coronary risk factors and their interaction. J. Am. Coll. Cardiol. 1994, 24, 1468-1474. [CrossRef]

(C) 2020 by the authors. Licensee MDPI, Basel, Switzerland. This article is an open access article distributed under the terms and conditions of the Creative Commons Attribution (CC BY) license (http://creativecommons.org/licenses/by/4.0/). 